\title{
Article \\ Water Carrying Capacity Evaluation Method Based on Cloud Model Theory and an Evidential Reasoning Approach
}

\author{
Wenzhi Cao, Jilin Deng (D), Yi Yang *(D), Yangyan Zeng and Limei Liu
}

check for updates

Citation: Cao, W.; Deng, J.; Yang, Y.; Zeng, Y.; Liu, L. Water Carrying Capacity Evaluation Method Based on Cloud Model Theory and an Evidential Reasoning Approach. Mathematics 2022, 10, 266. https:// doi.org/10.3390/math10020266

Academic Editor: Andreas

C. Georgiou

Received: 7 December 202

Accepted: 13 January 2022

Published: 16 January 2022

Publisher's Note: MDPI stays neutral with regard to jurisdictional claims in published maps and institutional affiliations.

Copyright: (C) 2022 by the authors. Licensee MDPI, Basel, Switzerland. This article is an open access article distributed under the terms and conditions of the Creative Commons Attribution (CC BY) license (https:// creativecommons.org/licenses/by/ $4.0 /$ )

\author{
School of Frontier Crossover Studies, Hunan University of Technology and Business, Changsha 410205, China; \\ wenzcao@hutb.edu.cn (W.C.); JLDeng@stu.hutb.edu.cn (J.D.); zyy@hutb.edu.cn (Y.Z.); \\ seagullm@hutb.edu.cn (L.L.) \\ * Correspondence: yiyang2018@hutb.edu.cn; Tel.: +86-182-2998-7706
}

\begin{abstract}
The scientific and reasonable evaluation of the carrying capacity of water resources is of guiding significance for solving the issues of water resource shortages and pollution control. It is also an important method for realizing the sustainable development of water resources. Aiming at an evaluation of the carrying capacity of water resources, an evaluation model based on the cloud model theory and evidential reasoning approach is studied. First, based on the existing indicators, a water resources evaluation index system based on the pressure-state-response (PSR) model is constructed, and a classification method of carrying capacity grade is designed. The cloud model theory is used to realize the transformation between the measured value of indicators and the degree of correlation. Second, to obtain the weight of the evaluation index, the weight method of the index weights model based on the entropy weight method and evidential reasoning approach is proposed. Then, the reliability distribution function of the evaluation index and the graded probability distribution of the carrying capacity of water resources are obtained by an evidential reasoning approach. Finally, the evaluation method of the carrying capacity of water resources is constructed, and specific steps are provided. The proposed method is applied to the evaluation of water resources carrying capacity for Hunan Province, which verifies the feasibility and effectiveness of the method proposed in the present study. This paper applies this method of the evaluation of the water resources carrying capacity of Hunan Province from 2010 to 2019. It is concluded that the water resources carrying capacity of Hunan Province belongs to III $\sim$, which is between the critical state and the strong carrying capacity state. The carrying capacity of the province's water resources is basically on the rise. This shows that the carrying capacity of water resources in Hunan Province is in good condition, and corresponding protective measures should be taken to continue the current state.
\end{abstract}

Keywords: cloud model theory; evidential reasoning approach; water resources carrying capacity

\section{Introduction}

With the development of modern society, there is also a rapid advancement in information, industrialization, and agricultural modernization, resulting in a serious shortage of water resources and water pollution. Due to this result, the contradiction between the supply and demand of water resources becomes increasingly prominent. Facing the problem of balancing the supply and demand of water resources, the carrying capacity of water resources should be considered to ensure the sustainable development of water resources. The evaluation of water resources carrying capacity is the main basis for the macro-control and rational allocation of water resources [1]. It is a comprehensive response to water resources, as well as the social, economic, and ecological environment, and has a guiding significance for the rational development and utilization of regional water resources [2].

The existing research on water resources carrying capacity includes a quantitative calculation analysis and qualitative comprehensive evaluation. The representative research methods include the conventional trend method, multi-objective analysis method, system 
dynamics method, and comprehensive evaluation method [3]. Qu et al. [4] evaluated the carrying capacity of water resources in the middle reaches of the Heihe River Basin by using a trend method according to water demand prediction. Wu et al. [5] constructed a multi-objective decision analysis model of water resources carrying capacity, aiming at the maximum gross national product, population, and pollutant emission of water resources, and applied it to the evaluation of water resources carrying capacity for the eastern plain area of Handan. Wang et al. [6] used the method of system dynamics to construct a dynamic model of the water resources carrying capacity for the Hetian area, simulated the carrying capacity of water resources in the Hetian area, and analyzed the sensitivity of the results. Duan et al. [7] selected eight influencing factors, such as water intake resource development rate and water resource utilization rate, as evaluation indexes and applied the fuzzy comprehensive evaluation method to evaluate the carrying capacity of Xinjiang water resources. In addition, some research work has been devoted to soft computing water carrying [8-10]. To obtain a more accurate prediction of the longitudinal dispersion coefficient (LDC), the general structure of the group method of data handling is modified by means of extreme learning machine conceptions [8]. The multiple-kernel support vector regression (MKSVR) algorithm is proposed to estimate the hard-to-measure parameters for measuring water quality parameters (WQPs) [9]. Four robust data-driven techniques (DDTs) based on the evolutionary algorithms and classification concepts are developed to present formulations for the prediction of groundwater quality index (GQI) values in the case study of Rafsanjan Plain [10].

From what has been discussed above, there are still some shortcomings to the existing water resources carrying capacity evaluation research. Firstly, the indexes in the evaluation process are mostly selected subjectively, and the limitation is that the selection of evaluation indexes is arbitrary and non-systematic, causing the evaluation results to often be biased. Secondly, the allocation of index weight is subjective, and qualitative or quantitative methods are used to assign the weight. Thirdly, the evaluation process of water resources carrying capacity is stochastic and fuzzy, and the information is uncertain because it is affected by economic, social, and ecological factors. The above methods do not consider those problems.

In recent years, the rapid development of uncertain information processing theories and methods has brought new solutions, means, and methods to practical uncertain problems, formed a series of uncertain information decision-making theories and methods, and been widely used and expanded. For example, in the aspect of information representation and processing, scholars creatively put forward the recently concerned proportional hesitant fuzzy linguistic term set [11], possibility distribution hesitant fuzzy linguistic term set [12,13] and interval-valued type-2 fuzzy sets [14,15], and these decision-making methods skillfully combine the theory of the fuzzy set and linguistic term set, and can effectively deal with decision-making problems with qualitative and quantitative characteristics; In terms of group decision making, scholars focus on large-scale group decision-making problems and developed a series of consensuses reaching decision-making methods, which effectively improves the reliability of the decision-making process and the credibility of the decision-making results [16-19]. Some methods to deal with fuzzy problems provided by fuzzy set theory can solve the fuzzy information fusion problem. Using fuzzy set theory to solve the problem of multi-sensor information fusion can overcome the defects of traditional methods, such as a large amount of calculation and result conflict. The membership functions of fuzzy sets are given by experts empirically with a strong subjective will. In addition to the above related research on fuzzy sets, a cloud model theory and evidential reasoning approach are two kinds of uncertain information theories and methods that have developed rapidly in recent years. The advantages of evidential reasoning and cloud model theory are provided as follows: (i) a cloud model can realize the uncertainty transformation between qualitative concepts expressed by linguistic values and a quantitative numerical description; (ii) evidence theory can deal with uncertainty caused by 
randomness and ambiguity; (iii) evidence theory does not require prior probability and conditional probability.

Among many uncertainties, randomness and fuzziness are the most basic. The cloud model theory, proposed by academician and Chinese scholar Li Deyi, is a transformation model between the description and quantitative expression of uncertain language values, integrating the fuzziness and randomness of uncertain language values [20]. The cloud model theory can better depict the randomness and fuzziness of qualitative concepts and quantitative numerical transformation and has been widely used in fuzzy evaluation, multi-attribute decision making, and risk measurement, among others [21-24]. In view of the randomness and subjectivity of the selection of conventional membership functions, which cannot solve the problem of effective conversion between an accurate value and qualitative evaluation value, Shen et al. [25] applied the cloud model theory to replace the membership function and applied it in the field of food product quality evaluation. The evidential reasoning approach has outstanding advantages in processing fuzzy information and uncertain information and can simply and effectively synthesize different expert opinions, which has been widely used in group decision making, multi-objective identification, performance evaluation, and trend prediction [26-30]. In view of the problem that superposition and summary are often used in multi-source data fusion at the present stage, which may easily lead to inaccurate evaluation results, $\mathrm{Hu}$ et al. [31] introduced evidential reasoning approach to perform an evidence recursive synthesis of indicators belonging to various levels and calculated the probability distribution of each level.

It can be seen from the detailed research that the cloud model theory and evidential reasoning approach can better deal with the above problems, and these problems also exist in the evaluation of the water resources carrying capacity. Based on the above analysis, the PSR model was used to build the evaluation index system, and the cloud model theory was used to calculate the index grade correlation degree. At the same time, considering that the results obtained by the cloud model theory used to calculate the index grade correlation degree did not meet the distribution of confidence, normalization was carried out. The evidential reasoning theory was then introduced to fuse the multi-source index grade correlation degree by taking advantage of its ability to deal with fuzzy and uncertain data fusion problems.

The main innovations in this study are provided as follows: (i) a water resources evaluation index system based on the pressure-state-response (PSR) model is constructed; (ii) the evaluation index weight model is developed by combing the entropy weight method and evidential reasoning approach; and (iii) the cloud model and evidence theory are organically combined, and an evaluation model of water resources carrying capacity is proposed.

A water resources evaluation index system based on the pressure-state-response (PSR) model is constructed, and the classification method of carrying capacity grade is designed. The cloud model theory is used to realize the transformation between the measured value of indicators and the degree of correlation. Second, to obtain the weight of the evaluation index, the weight method of the index weights model based on the entropy weight method and evidential reasoning approach is proposed. Then, the reliability distribution function of the evaluation index and the graded probability distribution of the carrying capacity of water resources are obtained by an evidential reasoning approach. Finally, the evaluation method of the carrying capacity of water resources is constructed, and specific steps are provided. The proposed method is applied to the evaluation of the water resources carrying capacity for Hunan Province, which verifies the feasibility and effectiveness of the method proposed in the present study.

\section{Overview of the Study Area and Data Sources}

\subsection{Study Area Overview}

Hunan Province is located at $24^{\circ} 38^{\prime} \sim 30^{\circ} 08^{\prime}$ north latitude and $108^{\circ} 47^{\prime} \sim 114^{\circ} 15^{\prime}$ east longitude. The total area comprises about 21,800 square kilometers. Hunan is located in the transition zone from the Yunnan-Guizhou Plateau to Jiangnan Hills and from the 
Nanling Mountains to Jianghan Plain. The terrain is a horseshoe landform surrounded by mountains on three sides and opening to the north. It is composed of plains, basins, hills, mountains, rivers, and lakes, and straddles the Yangtze River and Pearl River. The Xiangjiang River is the largest river in Hunan Province and the main river of Dongting Lake in the Yangtze River Basin. Its birthplace is the Ziliang Yao autonomous township of Lanshan County, Yongzhou City, Hunan Province. The trunk stream of the Xiangjiang River is $844 \mathrm{~km}$ long, with a drainage area of 94,660 square kilometers, flowing through Yongzhou, Hengyang, Zhuzhou, Xiangtan, Changsha, Yueyang, and six other cities.

\subsection{Data Sources}

In this paper, the per capita gross domestic product (GDP), population density, water consumption per ten thousand yuan of GDP, water consumption per ten thousand yuan of industrial production, water resources development and utilization rate, river water quality compliance rate, and twelve other index data of Hunan Province from 2010 to 2019 are reviewed. The data in this paper are from "The Statistical Yearbook of Hunan Province" from 2010 to 2019 (http:/ / tjj.hunan.gov.cn/tjsj/tjnj/ (accessed on 1 December 2021)) and "The Bulletin of Water Resources of Hunan Province" from 2010 to 2019 (http:/ / slt.hunan. gov.cn/slt/xxgk/tigb/index.html (accessed on 1 December 2021)).

\section{Problem Description and Preliminary Knowledge}

\subsection{Description of Water Resources Carrying Capacity Evaluation}

This paper takes Hunan Province as the object and builds a complete index system reasonably and scientifically based on factors related to population, economy, resources, and the environment to provide evaluation criteria for the evaluation model, such as population density, water quality compliance rate, per capita GDP, and other indicators. See Section 3.1 for the specific index construction process. Based on the constructed evaluation index system, this study proposes an evaluation method of water resources carrying capacity based on the cloud model theory and evidential reasoning approach.

Taking Hunan Province as the research object, this paper selects twelve indicators, including population density, urbanization rate, GDP growth rate, water resources development and utilization rate, water consumption per ten thousand yuan of GDP, water consumption per ten thousand yuan of industrial added value, per capita water resources, per capita domestic water consumption, per capita GDP, ecological environment water consumption rate, forest coverage rate, and water quality compliance rate. The cloud model theory and evidential reasoning approach were used to evaluate the water resources carrying capacity of Hunan Province from 2010 to 2019.

\subsection{Preliminary Knowledge}

In this paper, the cloud model theory and evidential reasoning approach should be taken as the basis for the evaluation method of water resources carrying capacity. This section primarily reviews the basic knowledge of the cloud model theory and evidential reasoning approach.

\subsubsection{Cloud Model Theory}

The cloud model theory, proposed by academician and Chinese scholar Li Deyi, is a transformation model between the description and quantitative expression of uncertain language values, integrating the fuzziness and randomness of uncertain language values [14] The forward cloud generator and reverse cloud generator in cloud model theory evaluation methods can realize the two-way transformation between qualitative and quantitative, which can effectively overcome the uncertainty problems in the evaluation process [32].

Definition 1. Let $X$ be a numerical quantity field and let $C$ be a qualitative concept of $X$. If the quantity value $x \in X, X$ is a random quantity on $C$. Then the membership degree $\mu(x) \in[0,1]$, 
where $x \sim N\left(E_{x}, E_{n}^{\prime 2}\right), E_{n}^{\prime} \sim N\left(E_{n}, H_{e}^{2}\right)$, the distribution of cloud model theory on $x, x$ of the cloud model theory for $\left(E_{x}, E_{n}, H_{e}\right)$, and point $(x, \mu(x))$ is called cloud droplets.

1. Expectation $E_{x}$ is the point that best represents the stereotype concept, and its value is usually taken as the expectation of points in the theory domain.

2. Entropy $E_{n}$, which can measure the randomness of a qualitative concept, can determine the range of cloud droplets consistent with the qualitative concept in the domain space.

3. Superentropy $H_{e}$ is the uncertainty measure of entropy, also known as the entropy of entropy. Its value depends on the fuzziness and randomness of entropy and reflects the degree of cloud droplet aggregation.

The cloud generator is a cloud generator algorithm. The forward cloud generator is a qualitative to quantitative mapping that forms cloud droplets according to the digital characteristics of clouds $\left(E_{x}, E_{n}, H_{e}\right)$. The specific steps are:

1. Create an expected $E_{x}$ and generate a normal random number $x_{i}$ with the variance $E_{n}$.

2. Create an expectation $E_{n}$ and generate a normal random number $y_{i}$ with the variance $H_{e} /$

3. Calculation of $\mu(x)=\exp \left(\frac{-\left(x_{i}-y_{i}\right)}{2 E_{n_{i j}}^{\prime 2}}\right),(x i, \mu(x))$ as the cloud droplets.

4. Repeat Steps 1-3 until the nth qualified cloud droplet forms a cloud.

\subsubsection{Evidential Reasoning Approach}

Evidence theory was first proposed by Dempster [33] and then systematically improved by Shafer [34], and, as such, is also known as the Dempster-Shafer (D-S) theory, which is a method of uncertain reasoning. Evidence theory includes three main points: basic probability assignment function, trust function, and likelihood function. It is used to extract data from different information sources and obtain the solution of the problem by orthogonal summation.

In D-S evidence theory, the identification frame is the proposition that all possible sets and unique information sources provide evidence. $\theta$ is defined as a finite complete set of $N$ mutually exclusive elements.

$$
\theta=\left\{\theta_{1}, \theta_{2}, \theta_{3}, \ldots, \theta_{N}\right\}
$$

The identification frame is the set of all possible outcomes of the decision problem, denoted by $2^{\theta}$ :

$$
2^{\theta}=\left\{\varnothing,\left\{\theta_{1}\right\}, \ldots,\left\{\theta_{N}\right\},\left\{\theta_{1}, \theta_{2}\right\}, \ldots,\left\{\theta_{1}, \theta_{N}\right\}, \ldots, \theta\right\}
$$

Definition 2. If there is a set function $m: 2^{\theta} \rightarrow[0,1]$, then $m$ is a basic probability distribution on $\theta$, also referred to as the mass function. $m(A)$ represents the degree of evidence supporting proposition A. If $m(A)>0, A$ is the fundamental probability on $\theta$, and the focal element of $m$ is assigned.

Let $m_{1}$ and $m_{2}$ be two groups of basic probability assignments, the corresponding focal element is $A_{1}, \ldots, A_{k}$ and $B_{1}, \ldots, B_{l}$, and $m$ represents the combined evidence. Dempster's combination rule is as follows:

$$
\left\{\begin{array}{c}
m(\varnothing)=0 \\
m(A)=\frac{1}{1-k} \sum_{A_{i} \cap B_{j}=A} m_{1}\left(A_{i}\right) m_{2}\left(B_{j}\right)
\end{array}\right.
$$


where $k=\sum_{A_{i} \cap B_{j}=O} m_{1}\left(A_{i}\right) m_{2}\left(B_{j}\right)$ is used to measure the degree of conflict between focal elements of evidence. The greater $k$ is, the greater the conflict is. If $k=1$, the combination rule becomes invalid.

\section{Water Resources Carrying Capacity Evaluation Method}

First, the evaluation index system of water resources carrying capacity is constructed based on the PSR model. Then, referring to the previous classification, the cloud model theory is selected to divide the evaluation grade interval, and the correlation degree of the grade index is calculated. The weight set of the index is then determined by the comprehensive weight method of dynamic and static combination. Finally, according to the evidential reasoning approach, the grade correlation degree of the evaluation index is fused.

\subsection{Construction of Evaluation Index System of Water Resources Carrying Capacity}

There are many factors affecting water resources carrying capacity, so the selection of evaluation indexes is very critical. The selection of indicators should follow the principles of comprehensiveness, scientificity, operability, and timeliness. Based on the evaluation index system constructed by scholars, the PSR model builds the evaluation index system of water resources carrying capacity in Hunan Province both comprehensively and hierarchically. Twelve main indicators, such as per capita GDP and population density, were obtained and are, respectively, expressed by $\times 1$ to $\times 12$ (Table 1 ).

Table 1. Evaluation index system of water resources carrying capacity in the study area.

\begin{tabular}{|c|c|c|c|c|c|}
\hline Target Layer & Factor Layer & Index Layer & Index Symbol & Meaning & Index Properties \\
\hline \multirow{12}{*}{$\begin{array}{l}\text { Water resources } \\
\text { carrying capacity } \\
\text { evaluation }\end{array}$} & \multirow{4}{*}{ Pressures $(\mathrm{P})$} & \multirow{4}{*}{$\begin{array}{c}\text { Population density } \\
\left(\text { person } / \mathrm{km}^{2}\right)[35-38] \\
\text { Urbanization rate }(\%) \\
{[35,37,38]} \\
\text { Growth rate of GDP }(\%) \\
{[35,37,38]} \\
\text { Utilization rate of water } \\
\text { resources development }(\%) \\
{[35-37]}\end{array}$} & $\times 1$ & Population pressure & Negative indicator \\
\hline & & & $\times 2$ & $\begin{array}{l}\text { Urban development } \\
\text { pressure }\end{array}$ & Negative indicator \\
\hline & & & $\times 3$ & Economic growth pressure & Negative indicator \\
\hline & & & $\times 4$ & $\begin{array}{c}\text { Water resources } \\
\text { development and } \\
\text { utilization of pressure }\end{array}$ & Negative indicator \\
\hline & \multirow{4}{*}{ States $(S)$} & $\begin{array}{c}\text { Water use per } 10^{4} \text { Yuan of } \\
\operatorname{GDP}\left(\mathrm{m}^{3} / 10^{4} \text { Yuan }\right) \\
{[35,37-39]}\end{array}$ & $\times 5$ & $\begin{array}{l}\text { Water consumption of gross } \\
\text { product }\end{array}$ & Negative indicator \\
\hline & & $\begin{array}{l}\text { Water use per } 10^{4} \text { Yuan of } \\
\text { industrial production } \\
\left(\mathrm{m}^{3} / 10^{4} \text { Yuan) [35-40] }\right. \\
\text { Water resources in per }\end{array}$ & $\times 6$ & Industrial structure & Negative indicator \\
\hline & & $\begin{array}{c}\text { capita terms }\left(\mathrm{m}^{3} / \text { person }\right) \\
{[35-40]}\end{array}$ & $\times 7$ & Water resources per capita & Positive indicators \\
\hline & & $\begin{array}{c}\text { Water consumption per } \\
\text { capital }\left(\mathrm{m}^{3} / \text { capital }\right) \\
{[36,37,39,40]}\end{array}$ & $\times 8$ & $\begin{array}{l}\text { Water consumption per } \\
\text { capita }\end{array}$ & Negative indicator \\
\hline & \multirow{4}{*}{ Responses (R) } & $\begin{array}{c}\text { GDP per capita }\left(10^{4}\right. \\
\text { Yuan/person) }[35,37,38]\end{array}$ & $\times 9$ & $\begin{array}{l}\text { Level of economic } \\
\text { development }\end{array}$ & Negative indicator \\
\hline & & $\begin{array}{c}\text { Percentage of ecological } \\
\text { water utilization }(\%) \\
{[35,37,39,40]}\end{array}$ & $\times 10$ & $\begin{array}{l}\text { Level of environmental } \\
\text { protection }\end{array}$ & Positive indicators \\
\hline & & $\begin{array}{l}\text { Percentage of forest cover } \\
(\%)[35-40]\end{array}$ & $\times 11$ & Greening level & Positive indicators \\
\hline & & $\begin{array}{c}\text { Rate of river water quality } \\
\text { up to standard }(\%) \\
{[35,36,38,40]}\end{array}$ & $\times 12$ & Water quality level & Positive indicators \\
\hline
\end{tabular}

\subsection{Evaluation Grade Standard}

The evaluation standard of water resources carrying capacity should accurately and objectively measure the coordinated development degree among the regional population, economy, resources, and environment. Peng Tao, Zuo Qiting, Zhang Lijie, Zuo Zhaohui, Wan Xichao, and Wang Gang have divided different levels of water resources' carrying 
capacity according to the characteristics of the study area. In this paper, the evaluation standard of the water resources carrying capacity of Hunan province is divided into five grades, I $\sim$, representing serious overload, overload, critical, weak carrying capacity, and strong carrying capacity (Table 2).

Table 2. Evaluation index grade standard.

\begin{tabular}{|c|c|c|c|c|c|}
\hline \multirow[b]{2}{*}{ Evaluation Indicator } & \multicolumn{5}{|c|}{ Assessment Level } \\
\hline & $\begin{array}{c}\text { I } \\
\text { (Serious } \\
\text { Overload) }\end{array}$ & $\begin{array}{c}\text { II } \\
\text { (Overload) }\end{array}$ & $\begin{array}{c}\text { III } \\
\text { (Critical) }\end{array}$ & $\begin{array}{c}\text { IV } \\
\text { (Weak Carrying } \\
\text { Capacity) }\end{array}$ & $\begin{array}{c}\text { V } \\
\text { (Strong Carrying } \\
\text { Capacity) }\end{array}$ \\
\hline$\times 1$ & $>300$ & 100 & 50 & 25 & $<25$ \\
\hline$\times 2$ & $>70$ & 60 & 50 & 40 & $<40$ \\
\hline$\times 3$ & $>30$ & 30 & 20 & 15 & $<15$ \\
\hline$\times 4$ & $>45$ & 45 & 30 & 15 & $<15$ \\
\hline$\times 5$ & $>400$ & 400 & 200 & 100 & $<100$ \\
\hline$\times 6$ & $>220$ & 220 & 140 & 60 & $<60$ \\
\hline$\times 7$ & $<1700$ & 1700 & 2300 & 3000 & $>3000$ \\
\hline$\times 8$ & $>100$ & 100 & 95 & 90 & $<90$ \\
\hline$\times 9$ & $>7.74$ & 7.74 & 2.5 & 0.66 & $<0.66$ \\
\hline$\times 10$ & $<2$ & 2 & 3 & 5 & $>5$ \\
\hline$\times 11$ & $<20$ & 20 & 35 & 55 & $>55$ \\
\hline$\times 12$ & $<70$ & 70 & 80 & 90 & $>90$ \\
\hline
\end{tabular}

\subsection{Evaluation Index Grade Correlation Degree Based on the Cloud Model Theory}

It is assumed that there are $M$ indicators in the index system, and each indicator is divided into $N[0,1]$ grades. According to the cloud model " $3 E_{n}$ rule", the digital characteristics of cloud model $\left(E_{x_{i j}}, E_{n_{i j}}, H_{e_{i j}}\right)$ on the interval $\left(s_{i j m i n}, s_{i j m a x}\right)$ correspond to any $i$ th evaluation index $j$, where $i=1,2, \ldots, M$ and $j=1,2, \ldots, N$. For the cloud model with bilateral constraints $\left[s_{\min }, s_{\max }\right]$, the formula of its numerical characteristics is

$$
\begin{aligned}
E_{x_{i j}}= & \frac{N_{i j m a x}+N_{i j m i n}}{2} \\
E_{n_{i j}}= & \frac{N_{i j m a x}-N_{i j m i n}}{6} \\
E_{n_{i j}}^{\prime}= & E_{n_{i j}}+H_{e_{i j}} \text { rand }()
\end{aligned}
$$

where $K$, as a constant, can be modulated according to the fuzzy threshold of the variable. The uniform value of $K$ in this study is 0.01 . For any sample, the correlation degree of $x_{i}$, the measured value of the $i$ th evaluation index belonging to the $j$ th level, is

$$
\mu_{i j}(x)=\exp \left(\frac{-\left(x_{i}-E_{x_{i j}}\right)}{2 E_{n_{i j}}^{\prime 2}}\right)
$$

\subsection{Index Weight Model Based on Entropy Weight Method and Evidential Reasoning Approach}

The weight value obtained by the entropy weight method avoids the problem of subjective arbitrariness. However, the weight value obtained only by the entropy weight method has poor universality and participation and cannot fully reflect the subjective cognition degree of decision makers. In addition, the combination weighting method combining subjective and objective factors does not consider the correlation between attributes or factors, but the evidence theory weight method uses the compatibility coefficient to describe the correlation of evidence, so the entropy weight method combining dynamic 
and static state and the index weight model of evidence theory is used to calculate the index weight.

\subsubsection{Weight Coefficient Determination Based on Entropy Weight Method}

The sample $e(e=1,2, \ldots \ldots, E)$, the measured value of the $i$ th evaluation index, is normalized to obtain $x_{i e}^{\prime}$, and the weight coefficient $\omega_{i}^{e n}$ of the $i$ th evaluation index is

$$
\begin{aligned}
& H_{i}=-\frac{\sum_{e=1}^{E} x_{i e}^{\prime} \ln x_{i e}^{\prime}}{\ln E} \\
& w_{i}^{e n}=\frac{1-H_{i}}{N-\sum_{t=1}^{N} H_{i}}
\end{aligned}
$$

4.4.2. Determination of Weight Coefficient Based on Evidential Reasoning Approach

To meet the requirements of evidence fusion, the index grade correlation degree matrix is transformed to make the correlation degree $\mu_{i j}$ meet the definition of probability assignment and facilitate the determination of dynamic weight. The calculation model is as follows:

$$
\mu_{i j}^{\prime}=\frac{\mu_{i j}}{\sum_{j=1}^{N} \mu_{i j}}, i=1,2, \ldots, N
$$

where $\mu_{i j}^{\prime}$ represents the basic probability distribution of the $i$ th evaluation index to the $j$ th grade. With the arbitrary evidence vector $q_{i}=\left\{\mu_{i 1}^{\prime}, \mu_{i 2}^{\prime}, \ldots, \mu_{\mathrm{iN}}^{\prime}\right\}$, then for any two evidence vectors $q_{i}$ and $q_{g}(i, g=1,2, \ldots, M)$, the consistency coefficient is

$$
\gamma_{i g}=\cos \left(q_{i}, q_{g}\right)=\frac{q_{i} q_{g}^{T}}{\left(q_{i} q_{i}^{T} q_{g} q_{g}^{T}\right)^{0.5}}
$$

Taking the evidence credibility after normalization of the absolute compatibility $\gamma_{i}$ of arbitrary evidence as the evaluation index fusion weight $\omega_{i}^{e v}$, the following is obtained:

$$
\begin{gathered}
\gamma_{i}=\sum_{g=1, i \neq g}^{M} \gamma_{i g} \\
\omega_{i}^{e v}=\frac{\gamma_{i}}{\sum_{i=1}^{M} \gamma_{i}}
\end{gathered}
$$

\subsubsection{The Comprehensive Weights}

In this paper, using the weight difference is consistent with the distribution coefficient difference principle. The weight coefficient is obtained by a calculation based on the entropy weight method $\omega_{i}^{\text {en }}$ and based on the combination of the weight coefficients of the evidence fusion $\omega_{i}^{e v}$ index weight $\omega_{i}$. Let the distribution coefficients of $\omega_{i}^{e n}$ and $\omega_{i}^{e v}$ be $\lambda_{1}$ and $\lambda_{2}$, respectively; then,

$$
\begin{gathered}
\lambda_{1}+\lambda_{2}=1, \lambda_{1}>\lambda_{2} \\
\omega_{i}=\lambda_{1} \omega_{i}^{e n}+\lambda_{2} \omega_{i}^{e v} \\
\sqrt{\sum_{i=1}^{n}\left(\omega_{i}^{e n}-\omega_{i}^{e v}\right)^{2}}=\sqrt{\left(\lambda_{1}-\lambda_{2}\right)^{2}}
\end{gathered}
$$

\subsection{Evaluation Index Grade Correlation Degree Fusion}

The evaluation index $e_{i}$ supports multiple evaluation levels at the same time. It is assumed that the probability distribution of evaluation index $e_{i}$ on evaluation level $N$ is 
expressed as $m\left(n / e_{i}\right)$ and simplified as $m_{i, n}$. The probability distribution of index $e_{i}$ on grade $n$ is expressed as follows:

$$
m_{i, n}=w_{i} \mu_{i, n}^{\prime}, i=1,2, \ldots, M, n=1,2, \ldots, N
$$

where $w_{i}$ is the normalized weight of the water quality index $e_{i}$.

Call $m_{i, H}$ the residual probabilities of the indicator $e_{i}$ that are not assigned to any single grade $H_{n}$, which are composed of $\bar{m}_{i, H}, \widetilde{m}_{i, H}$ :

$$
\begin{gathered}
m_{i, H}=\bar{m}_{i, H}+\widetilde{m}_{i, H} \\
\bar{m}_{i, H}=1-w_{i} \\
\widetilde{m}_{i, H}=w_{i}\left(1-\sum_{n=1}^{N} \mu_{i, n}^{\prime}\right)
\end{gathered}
$$

Make $m_{I(i), n}, \bar{m}_{I(i), H}$, and $\widetilde{m}_{I(i), H}$ to compile the first $i$ quality of the combination of the probability assessment. According to the above definition and calculation, the combined probability quality of the two assessments can be summarized by using Formulas (22)-(26).

$$
\begin{array}{r}
\left\{H_{n}\right\}: m_{I(i+1), n}=K_{I(i+1)}\left[m_{I(i), n} m_{i+1, n}+m_{I(i), H} m_{i+1, n}+m_{I(i), n} m_{i+1, H}\right], n=1,2, \ldots, N \\
m_{I(i), H}=\bar{m}_{I(i), H}+\widetilde{m}_{I(i), H} \\
\{H\}: \widetilde{m}_{I(i+1), H}=K_{I(i+1)}\left[\widetilde{m}_{I(i), H} \widetilde{m}_{i+1, H}+\bar{m}_{I(i), H} \widetilde{m}_{i+1, H}+\widetilde{m}_{I(i), H} \bar{m}_{i+1, H}\right], n=1,2, \ldots, N \\
\{H\}: \bar{m}_{I(i+1), H}=K_{I(i+1)}\left[\bar{m}_{I(i), H} \bar{m}_{i+1, H}\right] \\
K_{I(i+1)}=\left[\begin{array}{c}
1-\sum_{t=1}^{N} \sum_{j=1}^{N} m_{I(i), t} m_{i+1, j} \\
j \neq t
\end{array}\right]
\end{array}
$$

After the evaluation and summary of L indicators by using the above formula, the following two formulas are used to calculate the confidence degree of the combination.

$$
\begin{array}{r}
\{N\}: \mu_{n}=\frac{m_{I(L), n}}{1-\bar{m}_{I(L), H}}, n=1,2, \ldots \ldots, N \\
\{H\}: \mu_{H}=\frac{\widetilde{m}_{I(L), H}}{1-\bar{m}_{I(L), H}}, n=1,2, \ldots \ldots, N
\end{array}
$$

Suppose that $b$ represents the probability distribution vector supporting each grade:

$$
b=\left\{\mu_{n}, \mu_{H}\right\}, n=1,2, \ldots \ldots, N
$$

\section{Water Resources Carrying Capacity Evaluation Method and Its Application}

\subsection{Water Resources Carrying Capacity Evaluation Method}

Here, the steps of the entire evaluation process are described in detail.

Step 1: Considering the evaluation of $M$ evaluation indexes and $N$ evaluation grades of water resources carrying capacity, the decision matrix of evaluation indexes regarding evaluation grades was established, and the correlation degree of evaluation samples in evaluation grades was calculated. $E_{x_{i j}}, E_{n_{i j}}$, and $H_{e_{i j}}$ of the cloud model theory are calculated according to Formulas (4)-(7). Then, the grade correlation degree $\mu_{i j}$ is calculated according to Formula (8). 
Step 2: The entropy weight method was adopted to obtain the weight of indicators, and evidential reasoning approach was used to calculate the compatibility between indicators. According to Formulas (9) and (10), the entropy weight method weight coefficient $\omega_{i}^{\text {en }}$ is obtained, and the evidential reasoning approach weight coefficient $\omega_{i}^{e v}$ is calculated by Formulas (11)-(14).

Step 3: Using the principle that the weight difference is consistent with the distribution coefficient difference, the combined weight of dynamic and static combination is obtained. According to Formulas (15)-(17), the final index weight set $\omega_{i}$ is calculated.

Step 4: The probability distribution of each grade was calculated by using the degree of correlation and weight of the grade after processing, and then the grade probability was fused. According to Formula (18), the probability distribution of the indexes in all grades $m_{i, n}$ is calculated. According to Formulas (19)-(26), the combined probability quality generated by the first I evaluations are $m_{I(i), n}, \bar{m}_{I(i), H}$, and $\bar{m}_{I(i), H}$. Finally, the probability distribution vector $b$ of each grade is obtained by using Formulas (27)-(29).

\subsection{Case Analysis}

In the previous section, the evaluation process of the existing water resources carrying capacity was studied. Based on the research area of Hunan Province, the source of experimental data was given; the index system was constructed; the weight coefficient was determined; and the evaluation method was selected. Based on the above analysis, a case analysis was conducted for the data in Table 3. Considering the randomness, fuzziness, and information uncertainty in the evaluation process of water resources carrying capacity, this study constructed a method to evaluate water resources carrying capacity based on the cloud model theory and evidential reasoning approach from the evaluation index system and weight coefficient of the water resources carrying capacity. A practical case analysis will be described in detail in this section by providing specific steps.

Table 3. Index data of 2010.

\begin{tabular}{ccccccccccccc}
\hline$\times \mathbf{1}$ & $\times \mathbf{2}$ & $\times \mathbf{3}$ & $\times \mathbf{4}$ & $\times \mathbf{5}$ & $\times \mathbf{6}$ & $\times \mathbf{7}$ & $\times \mathbf{8}$ & $\times \mathbf{9}$ & $\times \mathbf{1 0}$ & $\times \mathbf{1 1}$ & $\times \mathbf{1 2}$ \\
\hline $\mathbf{2 9} .8791$ & 19.3 & 0.1798 & 19.3 & 249 & 173 & 2698.9 & 45.5 & 2.4004 & 3.2 & 57.01 & 77.1 \\
\hline
\end{tabular}

The evaluation index data of 2010 are selected as sample data (Table 3).

Step 1: Calculate $E_{x_{i j}}, E_{n_{i j}}$, and $H_{e_{i j}}$ equivalents of the cloud model theory according to Formulas (4)-(7) (Table 4).

Table 4. Classification of index system.

\begin{tabular}{|c|c|c|c|c|c|}
\hline \multirow{2}{*}{ The Evaluation Index } & \multicolumn{5}{|c|}{ Assessment Level } \\
\hline & I & II & III & IV & $\mathrm{V}$ \\
\hline$\times 1$ & $(350,16.67,0.01)$ & $(200,33.33,0.01)$ & $(75,8.33,0.01)$ & $(37.5,4.17,0.01)$ & $(12.5,4.17,0.01)$ \\
\hline$\times 2$ & $(65,1.67,0.01)$ & $(55,1.67,0.01)$ & $(45,1.67,0.01)$ & $(35,1.67,0.01)$ & $(15,5,0.01)$ \\
\hline$\times 3$ & $(32.5,0.83,0.01)$ & $(25,1.67,0.01)$ & $(17.5,0.83,0.01)$ & $(12.5,0.83,0.01)$ & $(5,1.67,0.01)$ \\
\hline$\times 4$ & $(52.5,2.5,0.01)$ & $(37.5,2.5,0.01)$ & $(22.5,2.5,0.01)$ & $(10,1.67,0.01)$ & $(2.5,0.83,0.01)$ \\
\hline$\times 5$ & $(500,33.34,0.01)$ & $(300,33.34,0.01)$ & $(150,16.65,0.01)$ & $(75,8.33,0.01)$ & $(25,8.31,0.01)$ \\
\hline$\times 6$ & $(270,16.66,0.01)$ & $(180,13.32,0.01)$ & $(100,13.32,0.01)$ & $(42,6.01,0.01)$ & $(12,3.99,0.01)$ \\
\hline$\times 7$ & $(250,83.33,0.01)$ & $(1100,200.01,0.01)$ & $(2000,100,0.01)$ & $(2650,116.65,0.01)$ & $(4000,333.33,0.01)$ \\
\hline$\times 8$ & $(102.5,0.83,0.01)$ & $(97.5,0.83,0.01)$ & $(92.5,0.83,0.01)$ & $(87.5,0.83,0.01)$ & $(42.5,14.17,0.01)$ \\
\hline$\times 9$ & $(8.87,0.38,0.01)$ & $(5.12,0.87,0.01)$ & $(1.58,0.31,0.01)$ & $(0.48,0.06,0.01)$ & $(0.15,0.05,0.01)$ \\
\hline$\times 10$ & $(0.5,0.17,0.01)$ & $(1.5,0.16,0.01)$ & $(2.5,0.16,0.01)$ & $(4,0.33,0.01)$ & $(6,0.33,0.01)$ \\
\hline$\times 11$ & $(5,1.67,0.01)$ & $(15,1.67,0.01)$ & $(27.5,2.5,0.01)$ & $(45,3.33,0.01)$ & $(60,1.67,0.01)$ \\
\hline$\times 12$ & $(30,10,0.01)$ & $(65,1.67,0.01)$ & $(75,1.67,0.01)$ & $(85,1.67,0.01)$ & $(95,1.67,0.01)$ \\
\hline
\end{tabular}


Then, calculate the grade correlation degree $\mu_{i j}$ according to Formula (8).

$$
\mu_{i j}=\left[\begin{array}{ccccc}
0 & 0 & 0 & 0.1885 & 0.0001 \\
0 & 0 & 0.5902 & 0 & 0 \\
0 & 0 & 0 & 0 & 0.015 \\
0 & 0 & 0.4378 & 0 & 0 \\
0 & 0.3103 & 0 & 0 & 0 \\
0 & 0.871 & 0 & 0 & 0 \\
0 & 0 & 0 & 0.9158 & 0.0004 \\
0 & 0 & 0 & 0 & 0.9778 \\
0 & 0.01 & 0.0414 & 0 & 0 \\
0 & 0.0003 & 0.2697 & 0 & 0 \\
0 & 0 & 0 & 0.0015 & 0.2051 \\
0 & 0 & 0.4629 & 0 & 0
\end{array}\right] .
$$

Step 2: According to Formulas (9) and (10), the weight coefficient of entropy weight method $\omega_{i}^{e n}$ is obtained.

$\omega_{i}^{e n}=[0.0003,0.0179,0.2501,0.0002,0.2426,0.2253,0.0748,0.0019,0.1474,0.0278,0.001,0.0107]$.

Then, according to Formula (11), the grade correlation degree $\mu_{i j}^{\prime}$ is calculated.

$$
\mu_{i j}^{\prime}=\left[\begin{array}{ccccc}
0 & 0 & 0 & 0.999 & 0.0009 \\
0 & 0 & 0.9999 & 0 & 0 \\
0 & 0 & 0 & 0 & 1 \\
0 & 0 & 0.9999 & 0 & 0 \\
0 & 0.9999 & 0 & 0 & 0 \\
0 & 0.9999 & 0 & 0 & 0 \\
0 & 0 & 0 & 0.9994 & 0 \\
0 & 0 & 0 & 0 & 1 \\
0 & 0.1949 & 0.805 & 0 & 0 \\
0 & 0.0014 & 0.9985 & 0 & 0 \\
0 & 0 & 0 & 0.0075 & 0.9924 \\
0 & 0 & 0.9999 & 0 & 0
\end{array}\right] .
$$

According to Formulas (12)-(14), the evidential reasoning approach weight coefficient $\omega_{i}^{e v}$ is obtained.

$\omega_{i}^{e v}=[0.0328,0.1292,0.065,0.1292,0.0402,0.0402,0.0328,0.065,0.1416,0.1293,0.0655,0.1292]$.

Step 3: Calculate the final index weight set $\omega_{i}$ according to Formulas (15)-(17).

$w_{i}=[0.0166,0.0736,0.1576,0.0646,0.1414,0.1327,0.0538,0.0334,0.1446,0.0786,0.0332,0.0699]$.

Step 4: According to Formulas (18)-(21), calculate the probability distribution $m_{i, n}$ of the index at all levels.

$$
\begin{gathered}
m_{1}^{1}=w_{1} \mu_{11}=0, m_{2}^{1}=0, m_{3}^{1}=0.07237, m_{4}^{1}=0.01535, m_{5}^{1}=0 . \\
\widetilde{m}_{H}^{1}=0, \bar{m}_{H}^{1}=0.9122, m_{H}^{1}=\widetilde{m}_{H}^{1}+\bar{m}_{H}^{1}=0.9122
\end{gathered}
$$

Similarly, the probability distribution and residual probability distribution of index $\times 2-\times 12$ in the five grades can be obtained. 
According to the above calculated results, according to Formulas (22)-(26), $m_{I(i), n}$, $\bar{m}_{I(i), H}$, and $\widetilde{m}_{I(i), H}$ are all created by the first I evaluations. The specific steps are as follows:

$$
\begin{aligned}
K_{I(2)} & =\left[1-\sum_{t=1}^{5} \sum_{\substack{j=1 \\
j \neq t}}^{5} m_{t}^{I(2)} m_{j}^{2}\right]^{-1}, i=1,2, \ldots \ldots, M-1=1.0012 . \\
m_{1}^{I(2)} & =0, m_{2}^{I(2)}=0, m_{3}^{I(2)}=0.0618, m_{4}^{I(2)}=0.0131, m_{5}^{I(2)}=0.1457 . \\
& \widetilde{m}_{H}^{I(2)}=0, \bar{m}_{H}^{I(2)}=0.7792, m_{H}^{I(2)}=\widetilde{m}_{H}^{I(2)}+\bar{m}_{H}^{I(2)}=0.7792 .
\end{aligned}
$$

Using the above results to continue the combined calculation, the final standard probability quality can be obtained as follows:

$$
\begin{gathered}
K_{I(5)}=1.0243 . \\
m_{1}^{I(5)}=0, m_{2}^{I(5)}=0.1712, m_{3}^{I(5)}=0.234, m_{4}^{I(5)}=0.0331, m_{5}^{I(5)}=0.1194 . \\
\widetilde{m}_{H}^{I(5)}=0, \bar{m}_{H}^{I(5)}=0.4421, m_{H}^{I(5)}=0.4421 .
\end{gathered}
$$

The comprehensive reliability is calculated according to Formulas (27)-(29), and the detailed process is as follows:

$$
\begin{gathered}
\mu_{1}=\frac{m_{1}^{I(5)}}{1-\bar{m}_{H}^{I(5)}}=0 . \\
\mu_{2}=\frac{m_{2}^{I(5)}}{1-\bar{m}_{H}^{I(5)}}=0.3069 . \\
\mu_{3}=\frac{m_{3}^{I(5)}}{1-\bar{m}_{H}^{I(5)}}=0.4195 . \\
\mu_{4}=\frac{m_{4}^{I(5)}}{1-\bar{m}_{H}^{I(5)}}=0.0593 . \\
\mu_{5}=\frac{m_{5}^{I(5)}}{1-\bar{m}_{H}^{I(5)}}=0.2141 . \\
\mu_{H}=\frac{\widetilde{m}_{H}^{I(5)}}{1-\bar{m}_{H}^{I(5)}}=0 .
\end{gathered}
$$

The final probability grade distribution vector $b$ is obtained:

$$
b=[0,0.3069,0.4195,0.0593,0.2141,0] .
$$

It can be concluded that the grade of water resources carrying capacity of Hunan Province in 2010 is III, indicating a critical water resources carrying capacity.

\subsection{Result Analysis and Method Comparison}

\subsubsection{Comparison of Weight Methods}

The comprehensive weight method can be degenerated into an entropy weight method and evidence theory method according to the distribution of coefficients. In this paper, the AHP method [41,42], entropy weight method, and evidence theory method are used to compare with the comprehensive weight method. The weight obtained by different 
methods is used to calculate the water resources carrying capacity of Hunan province in 2010 (Table 5).

Table 5. Comparison of weight methods.

\begin{tabular}{ccccc}
\hline AHP Method & $\begin{array}{c}\text { Evidential Reasoning } \\
\text { Approach }\left(\lambda_{1}=0, \lambda_{2}=1\right)\end{array}$ & $\begin{array}{c}\text { Entropy Weight } \\
\text { Method }\left(\lambda_{1}=1, \lambda_{2}=0\right)\end{array}$ & $\begin{array}{c}\text { Comprehensive Weight } \\
\text { Method }\left(\lambda_{1}=0.5, \lambda_{2}=0.5\right)\end{array}$ \\
\hline$\times 1$ & 0.0306 & 0.0328 & 0.0003 & 0.0166 \\
$\times 2$ & 0.079 & 0.1292 & 0.0179 & 0.0736 \\
$\times 3$ & 0.1828 & 0.065 & 0.2501 & 0.1576 \\
$\times 4$ & 0.0306 & 0.1292 & 0.0002 & 0.0646 \\
$\times 5$ & 0.1828 & 0.0402 & 0.2426 & 0.1414 \\
$\times 6$ & 0.1654 & 0.0402 & 0.2253 & 0.1327 \\
$\times 7$ & 0.079 & 0.0328 & 0.0748 & 0.0538 \\
$\times 8$ & 0.0306 & 0.065 & 0.0019 & 0.0334 \\
$\times 9$ & 0.079 & 0.1416 & 0.1474 & 0.1446 \\
$\times 10$ & 0.079 & 0.1293 & 0.0278 & 0.0786 \\
$\times 11$ & 0.0306 & 0.0655 & 0.0001 & 0.0332 \\
$\times 12$ & 0.0306 & 0.1292 & 0.0107 & 0.0699 \\
\hline Evaluation results & II & III & II & III
\end{tabular}

As can be seen from Table 5, the water resources carrying capacity of Hunan Province in 2010 was in II III, basically between the critical state and the overload state. Among them, the results obtained by AHP and entropy weight method are poor and belong to overload. AHP method itself is too subjective and cannot objectively reflect the importance of indicators in water resources carrying capacity. The entropy weight method itself only considers the importance of statistical significance of indicators but ignores the practical significance of water resources carrying capacity. It shows that too subjective or objective weight methods will affect the evaluation results. The advantage of comprehensive weight is that it can overcome the deficiency in single weight.

\subsubsection{Comparison of Evaluation Methods}

The evaluation results of water resources carrying capacity evaluation method based on the cloud model theory and evidential reasoning approach were obtained by the above calculation steps. This section compares the commonly used fuzzy comprehensive evaluation methods, cloud model theory, and evaluation methods based on cloud model theory and an evidential reasoning approach (Table 6).

Using the cloud model theory and the method of this paper to compare, it can be seen that the trend of water resources carrying capacity from 2010 to 2019 is basically the same. However, the method of this article fluctuated in 2018. It can be seen from the original data that the GDP growth rate and per capital water resources from 2017 to 2019 fluctuate in a V-shape, and the value of industrial water consumption per 10,000 yuan fluctuates in an inverted V-shape, with large fluctuations. The cloud model theory does not reflect this fluctuation in the evaluation results, and the method of this paper is more sensitive in comparison. Comparing the fuzzy comprehensive evaluation method with the method of this paper, it can be seen that the water resources carrying capacity has shown an overall upward trend from 2010 to 2019. Similarly, in the case of a small number of data that have large fluctuations, the fuzzy comprehensive evaluation method cannot reflect this fluctuation in the results. In addition, the fuzzy comprehensive evaluation method is too subjective, and the evaluation results are highly volatile. It can be seen that the method of this paper is more sensitive and stable in comparison. 
Table 6. Comparison of evaluation results and methods.

\begin{tabular}{|c|c|c|c|c|c|c|}
\hline \multirow{2}{*}{$\begin{array}{c}\text { Cloud Model Theory and Evidential } \\
\text { Reasoning Approach } \\
\text { Year }\end{array}$} & \multicolumn{5}{|c|}{ Assessment Level } & \multirow{2}{*}{ Evaluation Results } \\
\hline & I & II & III & IV & $\mathbf{V}$ & \\
\hline 2010 & 0 & 0.3069 & 0.4195 & 0.0593 & 0.2141 & III \\
\hline 2011 & 0 & 0.2031 & 0.4713 & 0.0004 & 0.3249 & III \\
\hline 2012 & 0 & 0.1052 & 0.4907 & 0.0602 & 0.3436 & III \\
\hline 2013 & 0 & 0.0942 & 0.6224 & 0.001 & 0.2822 & III \\
\hline 2014 & 0 & 0.1126 & 0.4859 & 0.0598 & 0.3415 & III \\
\hline 2015 & 0 & 0.1958 & 0.3672 & 0.064 & 0.3728 & $\mathrm{~V}$ \\
\hline 2016 & 0 & 0.1734 & 0.3291 & 0.0545 & 0.4428 & $\mathrm{~V}$ \\
\hline 2017 & 0 & 0.1978 & 0.1678 & 0.2571 & 0.377 & $\mathrm{~V}$ \\
\hline 2018 & 0 & 0.1055 & 0.3999 & 0.1432 & 0.3512 & III \\
\hline 2019 & 0 & 0.11 & 0.2333 & 0.2754 & 0.3811 & $\mathrm{~V}$ \\
\hline Fuzzy comprehensive evaluation method & I & II & III & IV & $\mathrm{V}$ & Evaluation results \\
\hline 2010 & 0 & 0.2678 & 0.281 & 0.25 & 0.2009 & III \\
\hline 2011 & 0.0165 & 0.2011 & 0.1748 & 0.3482 & 0.2591 & IV \\
\hline 2012 & 0.0095 & 0.1014 & 0.2483 & 0.3592 & 0.2814 & IV \\
\hline 2013 & 0.0057 & 0.1078 & 0.3678 & 0.2525 & 0.266 & III \\
\hline 2014 & 0.0165 & 0.0853 & 0.3585 & 0.2344 & 0.305 & III \\
\hline 2015 & 0.0155 & 0.1562 & 0.3457 & 0.1622 & 0.32 & III \\
\hline 2016 & 0.0091 & 0.1308 & 0.3346 & 0.1971 & 0.3281 & III \\
\hline 2017 & 0.0103 & 0.1257 & 0.2509 & 0.1353 & 0.4776 & $\mathrm{~V}$ \\
\hline 2018 & 0 & 0.1855 & 0.2766 & 0.0972 & 0.4405 & $\mathrm{~V}$ \\
\hline 2019 & 0 & 0.0907 & 0.2654 & 0.1915 & 0.4522 & $\mathrm{~V}$ \\
\hline Cloud Model Theory & I & II & III & IV & $\mathrm{V}$ & Evaluation results \\
\hline 2010 & 0 & 0.3038 & 0.4014 & 0.0705 & 0.2241 & III \\
\hline 2011 & 0 & 0.2246 & 0.4436 & 0.0006 & 0.331 & III \\
\hline 2012 & 0 & 0.1232 & 0.4569 & 0.0736 & 0.3461 & III \\
\hline 2013 & 0 & 0.1171 & 0.5734 & 0.0013 & 0.308 & III \\
\hline 2014 & 0 & 0.1304 & 0.4528 & 0.0729 & 0.3438 & III \\
\hline 2015 & 0 & 0.211 & 0.3524 & 0.0758 & 0.3606 & $\mathrm{~V}$ \\
\hline 2016 & 0 & 0.1922 & 0.3256 & 0.0629 & 0.4192 & $\mathrm{~V}$ \\
\hline 2017 & 0 & 0.2095 & 0.1749 & 0.2571 & 0.3582 & $\mathrm{~V}$ \\
\hline 2018 & 0 & 0.1212 & 0.3412 & 0.1543 & 0.3431 & $\mathrm{~V}$ \\
\hline 2019 & 0 & 0.1234 & 0.2386 & 0.2754 & 0.3625 & $\mathrm{~V}$ \\
\hline
\end{tabular}

It can be seen from Table 6 that 2015 is a turning point for the water resources carrying capacity of Hunan Province. Before 2015, the degree of development and pollution were large, and the carrying capacity of water resources was basically at a critical state. With the implementation of the concept of "no large-scale development", the carrying capacity of water resources reached a state of strong carrying capacity for 2015. However, the carrying capacity of water resources briefly returned to a critical state in 2018. It can be seen from this that in the future development of water resources carrying capacity, we must not only persist in not engaging in large-scale development, but more importantly, we must pay attention to large-scale protection.

\section{Conclusions}

The scientific and reasonable evaluation of water resources carrying capacity is a difficult problem in water environment management and governance. First, there is no mature and perfect theoretical basis for the determination of an index system. Second, there are subjective and experiential limitations in the process of establishing the weight of indicators. Finally, there is randomness, fuzziness, and information uncertainty in the evaluation process. Considering the shortcomings of the existing evaluation methods of water resources carrying capacity, the method proposed in this paper has the following advantages: 
1. The PSR model is used to construct an index system from three aspects of pressurestate-response to make the index selection more systematic and scientific.

2. The cloud model theory is used to describe the correlation degree of each index membership grade, and the randomness, fuzziness, and information uncertainty in the evaluation processes are taken into account to make the results more realistic.

3. In the process of weight determination, the combined weight method combining dynamic and static weights is adopted, and the evidence compatibility idea of the entropy weight method and evidential reasoning is introduced, which not only avoids the subjective defect of weight determination, but also reduces the distortion effect caused by the index conflict, making the result more objective and reasonable.

4. The improved evidentiary reasoning is used to fuse the correlation degree of each index belonging to the safety grade to obtain the final fusion probability of the comprehensive safety evaluation grade, which reduces the uncertainty of the results and improves the accuracy and reliability of the evaluation.

Author Contributions: Conceptualization, Y.Y. and W.C.; methodology, W.C., J.D. and Y.Y.; software, J.D.; validation, W.C., J.D. and Y.Z.; formal analysis, W.C. and Y.Y.; investigation, J.D. and Y.Z.; resources, W.C. and Y.Y.; data curation, J.D.; writing-original draft preparation, W.C. and J.D.; writing-review and editing, J.D., W.C. and Y.Y.; visualization, Y.Z. and L.L.; supervision, Y.Z. and L.L.; project administration, Y.Y. and W.C. All authors have read and agreed to the published version of the manuscript.

Funding: This research received no external funding.

Institutional Review Board Statement: Not applicable.

Informed Consent Statement: Not applicable.

Data Availability Statement: This research uses "The Statistical Yearbook of Hunan Province" from 2010 to 2019 (http:/ / tjj.hunan.gov.cn/tjsj/tjnj/, accessed on 1 December 2021) and "The Bulletin of Water Resources of Hunan Province" from 2010 to 2019 (http:/ / slt.hunan.gov.cn/slt/xxgk/tjgb / index.html, accessed on 1 December 2021).

Acknowledgments: This research was supported by the Ministry of education of Humanities and Social Science Foundation of China (No. 20YJCZH210), the National Natural Science Foundation of China (No. 61702183), the Natural Science Foundation of Hunan Province, China (No. 2020JJ5112); the Youth driven project of Hunan University of Technology and Business (Nos. 19QD03 and 17QD03); the Excellent youth project of scientific research of Hunan Provincial Department of education (Nos. 19B311 and 19B316).

Conflicts of Interest: The authors declare no conflict of interest.

\section{References}

1. Safavi, H.R.; Mehrparvar, M.; Szidarovszky, F. Conjunctive management of surface and ground water resources using conflict resolution approach. J. Irrig. Drain. Eng. 2016, 142, 05016001. [CrossRef]

2. Reziya, A.; Fang, C.L.; Zhao, R.D. Research on the water resources carrying capacity and spatial-temporal characteristics in Xinjiang. Resour. Environ. Yangtze Basin 2020, 29, 1576-1585.

3. Guo, Q.; Wang, J.Y.; Zhang, B. Comprehensive evaluation of the water resource carrying capacity based on DPSIRM. J. Nat. Resour. 2017, 32, 484-493.

4. Qu, Y.G.; Fan, S.Y. Water resources capacity and developing strategies in Heihe River Basin. J. Desert Res. 2000, 20, 2-9.

5. $\mathrm{Wu}, \mathrm{X}$; Liu, B.; Liu, J.; Wu, R.Z. Research on water resources carrying capacity based on multi-objective decision analysis. Water Resour. Power 2021, 39, 9+42-45.

6. Wang, C.; Yang, G.; He, X.L.; Chen, S.; Li, X.L.; Yang, M.J. Research on water resources carrying capacity based on system dynamics. China Rural Water Hydropower 2016, 39, 212-215+220.

7. Duan, X.G.; Luan, F.F. Evaluation of water resources carrying capacity in Xinjiang based on fuzzy comprehensive model. China Popul. Resour. Environ. 2014, 212-215+220.

8. Sabed-Movahed, F.; Najafzadeh, M.; Mehrpooya, A. Receiving More Accurate Predictions for Longitudinal Dispersion Coefficients in Water Pipelines: Training Group Method of Data Handling Using Extreme Learning Machine Conceptions. Water Resour. Manag. 2020, 34, 529-561. [CrossRef] 
9. Najafzadeh, M.; Niazmardi, S. A Novel Multiple-Kernel Support Vector Regression Algorithm for Estimation of Water Quality Parameters. Nat. Resour. Res. 2021, 30, 3761-3775. [CrossRef]

10. Najafzadeh, M.; Homaei, F.; Mohamadi, S. Reliability evaluation of groundwater quality index using data-driven models. Environ. Sci. Pollut. Res. 2021, 1-17. [CrossRef]

11. Chen, Z.S.; Chin, K.S.; Li, Y.L.; Yang, L. Proportional hesitant fuzzy linguistic term set for multiple criteria group decision making. Inf. Sci. 2016, 357, 61-87. [CrossRef]

12. Chen, Z.S.; Zhang, X.; Pedrycz, W.; Wang, X.J.; Martinez, L. K-means clustering for the aggregation of HFLTS possibility distributions: $N$-two-stage algorithmic paradigm. Knowl.-Based Syst. 2021, 227, 107230. [CrossRef]

13. Chen, Z.S.; Yang, Y.; Wang, X.J.; Chin, K.S.; Tsui, K.L. Fostering linguistic decision-making under uncertainty: A proportional interval type-2 hesitant fuzzy TOPSIS approach based on Hamacher aggregation operators and andness optimization models. Inf. Sci. 2019, 500, 229-258. [CrossRef]

14. Boral, S.; Chaturvedi, S.K.; Howard, L.; Naikan, V.N.A.; McKee, K. An integrated interval type-2 fuzzy sets and multiplicative half quadratic programming-based MCDM framework for calculating aggregated risk ranking results of failure modes in FMECA. Process Saf. Environ. Prot. 2021, 150, 194-222. [CrossRef]

15. Baykasoğlu, A.; Gölcük, İ. Development of an interval type-2 fuzzy sets based hierarchical MADM model by combining DEMATEL and TOPSIS. Expert Syst. Appl. 2017, 70, 37-51. [CrossRef]

16. Xiao, L.; Chen, Z.S.; Zhang, X.; Chang, J.P.; Chin, K.S. Bid evaluation for major construction projects under large-scale group decision-making environment and characterized expertise levels. Int. J. Comput. Intell. Syst. 2020, 13, 1227-1242. [CrossRef]

17. García-Zamora, D.; Labella, Á.; Rodríguez, R.M.; Martínez, L. Nonlinear preferences in group decision-making. Extreme values amplifications and extreme values reductions. Int. J. Intell. Syst. 2021, 36, 6581-6612. [CrossRef]

18. Rodríguez, R.M.; Labella, Á.; Sesma-Sara, M.; Bustince, H.; Martínez, L. A cohesion-driven consensus reaching process for large scale group decision making under a hesitant fuzzy linguistic term sets environment. Comput. Ind. Eng. 2021, 155, 107158. [CrossRef]

19. Rodríguez, R.M.; Labella, Á.; Dutta, B.; Martínez, L. Comprehensive minimum cost models for large scale group decision making with consistent fuzzy preference relations. Knowl.-Based Syst. 2021, 215, 106780. [CrossRef]

20. Liu, C.Y.; Li, D.Y.; Pan, L.L. Uncertain knowledge representation based on cloud model. J. Comput. Eng. Appl. $2004,40,32-35$.

21. Chen, D.H.; Xu, P.H.; Zhang, W.; Chen, J.P.; Song, S.Y.; Wang, Y.D. Evaluation of landslide hazard degree based on the normal cloud model. Int. J. Earth Sci. Eng. 2017, 10, 88-94.

22. Wen, S.; Zhu, J.J. A multistage risk decision making method for normal cloud model considering behavior characteristics. Appl. Soft Comput. J. 2019, 78, 393-406. [CrossRef]

23. Huang, G.Q.; Xiao, L.M. Failure mode and effect analysis: An interval-valued intuitionistic fuzzy cloud theory-based method Appl. Soft Comput. J. 2021, 98, 106834. [CrossRef]

24. Wei, H.; Qiao, P.L.; Zhou, Z.J. Reliability assessment of cloud computing platform based on semiquantitative information and evidential reasoning. J. Control Sci. Eng. 2016, 2016, 2670210. [CrossRef]

25. Shen, J.C.; Du, S.X.; Luo, Y.; Luo, J.Y.; Yang, Q.; Chen, Z.F. Method and application research on fuzzy comprehensive evaluation based on cloud model. Fuzzy Syst. Math. 2012, 26, 115-123.

26. Sun, X.B.; Tan, J.W.; Wen, Y.; Feng, C.S. Rolling bearing fault diagnosis method based on data-driven random fuzzy evidence acquisition and Dempster-Shafer evidence theory. Fuzzy Syst. 2016, 8. [CrossRef]

27. Fu, C.; Xue, M.; Chang, W.J.; Xue, D.; Yang, S. An evidential reasoning approach based on risk attitude and criterion reliability Knowl.-Based Syst. 2020, 199, 105947. [CrossRef]

28. Pan, X.H.; Wang, Y.M.; He, S.F. The evidential reasoning approach for renewable energy resources evaluation under interval type-2 fuzzy uncertainty. Inf. Sci. 2021, 576, 432-453. [CrossRef]

29. Chen, S.Q.; Wang, Y.M.; Shi, H.-L.; Zhang, M.J.; Lin, Y. Evidential reasoning with discrete belief structures. Inf. Fusion 2018, 41, 91-104. [CrossRef]

30. Si, Y.; Dong, F.; Lian, Q.Y.; Peng, W.Q.; Du, X.; Huang, A.P.; Wang, W.J.; Chen, X.K. Preliminary study on dynamic evaluation method of water quality based on multi-source monitoring and data fusion. Yellow Ellow River 2021, 43, 88-94.

31. Hu, D.B.; Cai, H.P.; Chen, X.H.; Meng, F.Y.; Luo, Y.P.; Pan, H.T. Comprehensive assessment of water quality based on evidential reasoning: Taking the Xiangjiang River as an example. Resour. Sci. 2019, 41, 2020-2031. [CrossRef]

32. Li, D.Y.; Liu, C.Y. Study on the universality of the normal cloud model. Eng. Sci. 2004, 6, 28-34.

33. Dempster, A.P. Upper and lower probabilities induced by a multivalued mapping. Ann. Math. Stat. 1967, 38, 325-339. [CrossRef]

34. Shafer, G. A Mathematical Theory of Evidence; Princeton University Press: Princeton, NJ, USA, 1976.

35. Peng, T.; Deng, H.W.; Lin, Y.; Jin, Z.Y. Assessment on water resources carrying capacity in karst areas by using an innovative DPESBRM concept model and cloud model. Sci. Total Environ. 2021, 767, 144353. [CrossRef]

36. Zuo, C.H.; Li, S.K.; Yang, J.J.; Yuan, Y.; Li, X. Research on water resources carrying capacity of shale gas development area based on GA-BP neural network. J. Environ. Eng. Technol. 2021, 11, 194-201.

37. Lu, J.H.; Tang, D.S. Study on water resources bearing capacity early warning based on PSR and matter-element extension model. Water Resour. Hydropower Eng. 2019, 50, 58-64.

38. Sun, D.L.; Wu, J.P.; Zhang, F.T.; Su, W.C.; Hui, H. Evaluating water resource security in karst areas using DPSIRM modeling, gray correlation, and matter-element analysis. Sustainability 2018, 10, 3934. [CrossRef] 
39. Zuo, Q.T.; Zhang, Z.Z.; Wu, B.B. Evaluation of water resources carrying capacity of nine provinces in Yellow River Basin based on combined weight. Water Resour. Prot. 2020, 36, 1-7.

40. Zhang, N.N.; Su, X.L.; Zhou, Y.Z.; Niu, J.P. Water resources carrying capacity evaluation of the Yellow River Basin based on EFAST weight algorithm. J. Nat. Resour. 2019, 34, 1759-1770. [CrossRef]

41. Boral, S.; Howard, L.; Chaturvedi, S.K.; McKee, K.; Naikan, V.N.A. An integrated approach for fuzzy failure modes and effects analysis using fuzzy AHP and fuzzy MAIRCA. Eng. Fail. Anal. 2020, 108, 104195. [CrossRef]

42. Stević, Ž.; Pamučar, D.; Puška, A.; Chatterjee, P. Sustainable supplier selection in healthcare industries using a new MCDM method: Measurement of alternatives and ranking according to COmpromise solution (MARCOS). Comput. Ind. Eng. 2020, 140, 106231. [CrossRef] 